University of the Pacific

Scholarly Commons

All Faculty Articles - School of Engineering and Computer Science

All Faculty Scholarship

$9-1-2014$

\title{
Serious Fun: Using toys to demonstrate fluid mechanics principles
}

Camilla M. Saviz

University of the Pacific, csaviz@pacific.edu

Said Shakerin

University of the Pacific, sshakerin@pacific.edu

Follow this and additional works at: https://scholarlycommons.pacific.edu/soecs-facarticles

Part of the Mechanical Engineering Commons

\section{Recommended Citation}

Saviz, C. M., \& Shakerin, S. (2014). Serious Fun: Using toys to demonstrate fluid mechanics principles.

Physics Teacher, 52(6), 332-335. DOI: 10.1119/1.4893085

https://scholarlycommons.pacific.edu/soecs-facarticles/88

This Article is brought to you for free and open access by the All Faculty Scholarship at Scholarly Commons. It has been accepted for inclusion in All Faculty Articles - School of Engineering and Computer Science by an authorized administrator of Scholarly Commons. For more information, please contact mgibney@pacific.edu. 


\section{Serious Fun: Using Toys to Demon- strate Fluid Mechanics Principles}

Camilla M. Saviz and Sald Shakern, University of the Pacific, Stockton, CA

$\mathrm{M}$ any students have owned or seen fluids toys in which two immiscible fluids within a closed container can be tilted to generate waves. These types of inexpensive and readily available toys are fun to play with, but they are also useful for provoking student learning about fluid properties or complex fluid behavior, including drop formation and coalescence. Including these toys in a class or lab with a companion exercise allows students to use observation and inductive reasoning to infer principles-all while having fun.

Different students can have very different learning needs based on a variety of factors including motivation, academic background, and approaches to studying, among others. ${ }^{1}$ Hands-on activities and demonstrations can diversify a class period and can help engage students, particularly if they have a preference for active learning. ${ }^{2}$ Demonstrations used in a variety of physics ${ }^{3-6}$ and engineering ${ }^{7-8}$ courses range from simple to complex setups, inexpensive and homemade devices, to elaborate, expensive, and commercially available units. ${ }^{9-12}$ YouTube $^{13-14}$ and other online video sources ${ }^{15-17}$ provide even more ideas for the effective use of toys and demonstrations in the classroom. Ludwig Prandtl was fascinated by toys. ${ }^{18}$ Wolfgang Pauli and Niels Bohr demonstrated the importance of observation and fun with a tippe top. ${ }^{19}$ The late Professor Julius Sumner Miller, who hosted many TV shows on physics demonstrations with simple devices and toys in the 1960 s and ${ }^{2} 70 \mathrm{~s},{ }^{13}$ found toys to be "enchanting." The rich body of literature on toys used in physics education ${ }^{20-22}$ is often relevant and applicable to engineering education since physics forms the foundation of engineering.

The use of toys and demonstrations, when well-planned, practiced, and introduced in support of class content, can liven

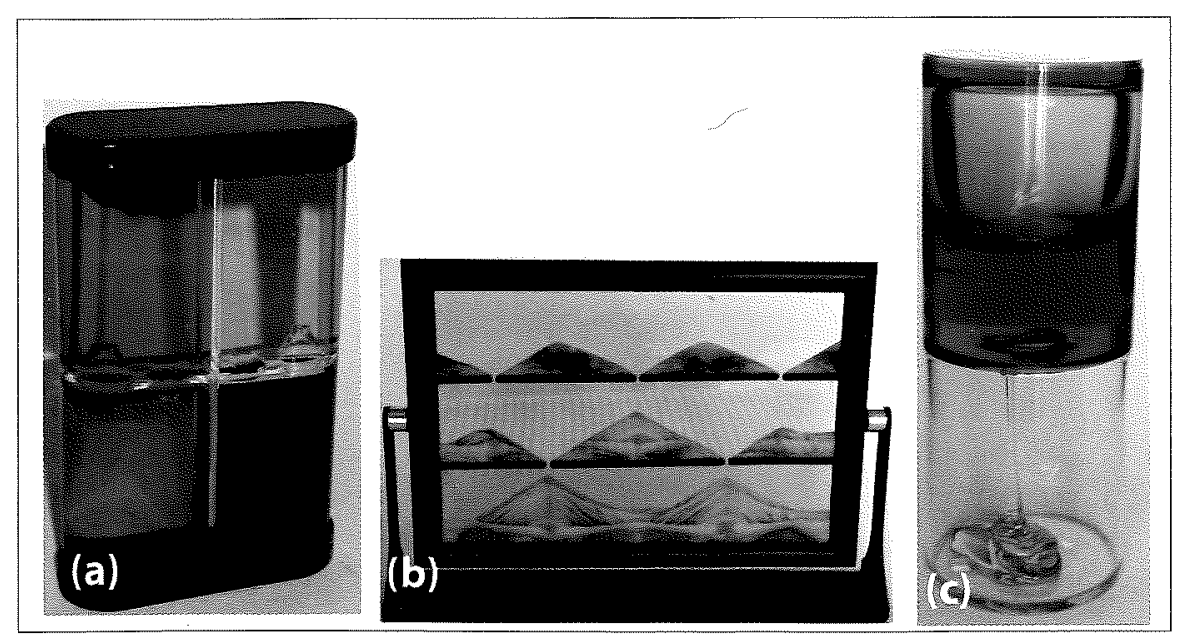

Fig. 1. Density differential and viscous fluid toys: (a) Colors in Motion ( $1 \times 3 \times 5$ in), (b) Sandscape (1/2 $\times 5 \times 7$ in), (c) Ooze Tube (3-in diameter $\times 8$ in). Toys (a) and (b) are trademarked by Westminster, Inc., Atlanta, GA. up the classroom ${ }^{7}$ and engage students. ${ }^{23}$ When accompanied by exercises that require thought, student interaction, interpretation of the demonstration, or prediction of outcomes, demonstrations can enhance student learning and retention of concepts. ${ }^{24-26}$ In this paper, we describe several fluids toys, present a method for using these toys to engage students in the process of learning about fluids, and present sample results used to gauge students' level of fundamental knowledge about the topic.

\section{Demonstrations with fluids toys}

Three inexpensive fluids-related toys that display an array of fluid mechanics phenomena are shown in Fig. 1. These toys cost $\$ 7$ to $\$ 11$ each (in 2013) and are available through online stores specializing in science and educational kits and at science museum gift shops. These toys and the phenomena they demonstrate are described below. Other toys are described in two related papers. ${ }^{27-28}$

Colors motion. This toy, shown in Fig. 1(a), is made of a clear plastic box and contains colored liquids in four equally sized chambers filled with dyed immiscible liquids of different densities. Each side of the box contains a small volume of air. Funnel-shaped openings connecting the top and bottom chambers on each side allow fluid exchange. The liquids and the walls are non-wetting. ${ }^{29}$ At its simplest level, the toy demonstrates the behavior of immiscible fluids of different densities and the effects of differences in density between gases and liquids. Guided observation may be used for students at the $\mathrm{K}-12$ level or for informal science education displays, while exercises that address some of the more complex fluid phenomena can be incorporated into fundamental or advanced science and engineering courses.

Figure 2 presents snapshots at different times after the box is inverted. The box was left undisturbed for a while prior to inversion to ensure that the liquids in each chamber were homogenous and without droplets or bubbles. Upon inversion, three distinct flow conditions are observed. First, the air quickly rises from the bottom to the top chambers with a rapid succession of air bubbles, causing rapid transfer of heavier liquid droplets from the top to the bottom chambers for about five to six seconds [Fig. 2(a)]. Second, after all the air has risen to the top, the liquids start replacing each other via slow and steady drop 


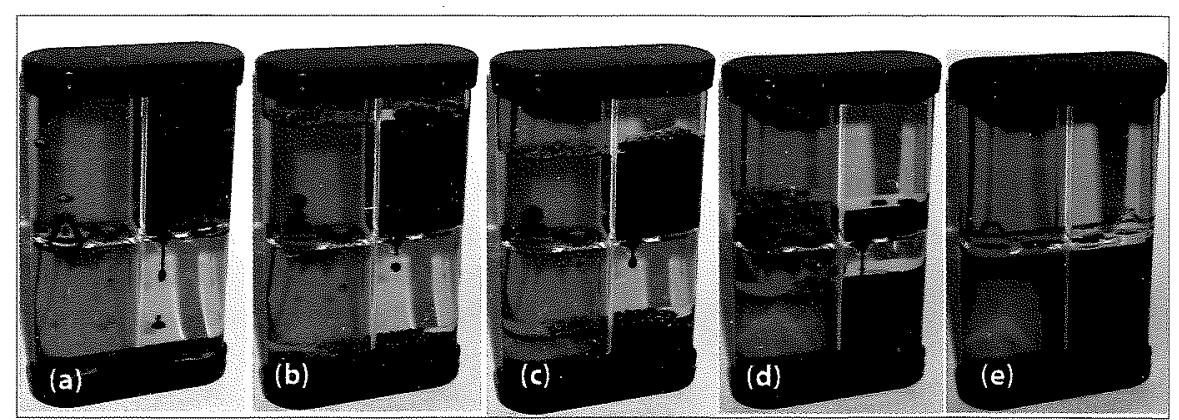

Fig. 2. Colors in Motion toy at different stages.
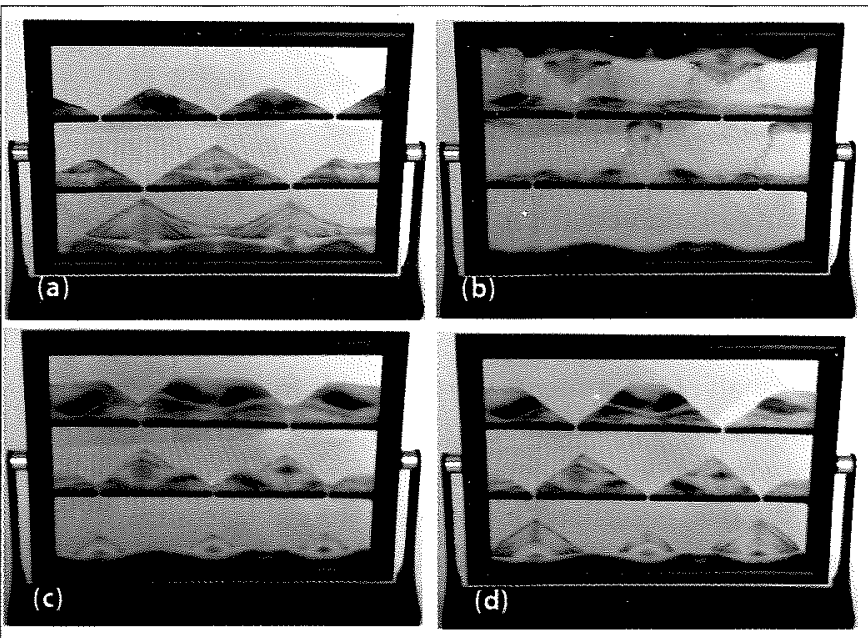

Fig. 3. (a) The instant before toy was inverted; (b) and (c) snap shots as sand falls down and air flows up; (d) sand painting at the end.

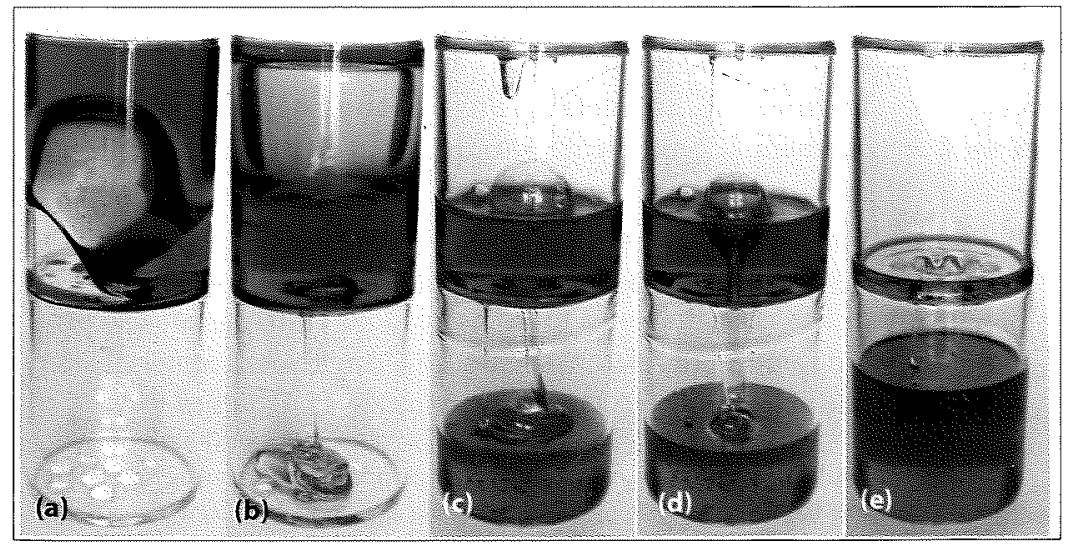

Fig. 4. The Ooze Tube. Various stages of bubble dynamics and liquid coiling demonstrated in a highly viscous liquid.

formation, with heavier drops falling and lighter drops rising [Figs. 2(b) and 2(c)]. Each drop is encased by a film of the other liquid through which it flows. As drops settle on their like liquid surfaces, they float for a while and then coalesce. This portion of the flow takes about 4.5 minutes. Third, the downward flows of drops change into streams when, before detachment from the opening, they touch their like liquid surface below [Fig. 2(d)]. Closer observation reveals buckling of the stream as it experiences a compressive force from below. This portion of the flow lasts several seconds, after which the funnel-shaped openings are covered by the other liquid. The liquid exchange continues until all liquids have completely filled their respective chambers. The entire sequence of motion takes a little over five minutes. Now the toy is ready to be inverted again and the above sequence repeated [Fig. 2 (e)].

Sandscape. This novelty toy, shown in Fig. 3, is a modified Hele-Shaw (HS) cell made of two plates separated by a small gap $(\approx 1 \mathrm{~mm})$ containing colored fine sand (black and green) and sand dust. The HS cell is a device that has been used by researchers to investigate two-dimensional flows. ${ }^{30}$ The sand fills approximately one-third of the space in the toy; the rest is typically filled with air or, sometimes, a liquid. The cell is divided into three equal horizontal sections with narrow strips of dividers with two or three small openings between each pair of adjacent sections, as shown in Fig. 3(a).

The toy is rotated along its horizontal axis in a frame with a base, upon which sand flows down and the fluid flows up to replace the space vacated by the sand, shown in Fig. 3(b). Elevated piles are formed underneath each opening as shown in Fig. 3(c). The sand piles so formed clearly exhibit the angle of repose-the angle created as granules fall freely-a common situation observed in transport of granular materials. It takes about six minutes for the motion of sand particles to come to rest, and then the toy is ready for another half turn to start a new sand painting [Fig. 3(d)]. This toy can be used to demonstrate behavior of non-cohesive sediments or granular materials, and to emphasize the relevance of soil material to bank stability in design of open channels made of natural materials.

\section{Ooze Tube. The Ooze Tube, shown in Fig. 4,} contains a highly viscous liquid-in this case, dyed blue for visual effect-that flows through an orifice plate partitioning a cylindrical vessel. The rest of the cylinder is filled with air. Different dynamic flow phenomena that can be observed with this novelty toy include the Rayleigh-Taylor instability [Fig. 4(a)] and liquid coiling [Figs. 4(b) and (c)]. Bubble dynamics that can be observed in slow mo tion include bubble formation, bubble pinch-off, and bubble burst, seen in Figs. 4(b)-(d), as several bubbles form sequentially through the process. It takes about 12 minutes for almost all of the liquid to drain into the bottom compartment [Fig. 4(e)]. The Ooze Tube can also be used in an exercise to estimate Reynolds numbers for laminar and turbulent flows. The viscosity of a similarly high-viscosity fluid such as honey or glycerin may be used together with measurements of the orifice diameter, the fall distance, and the fall time for the liquid stream to estimate the Reynolds 


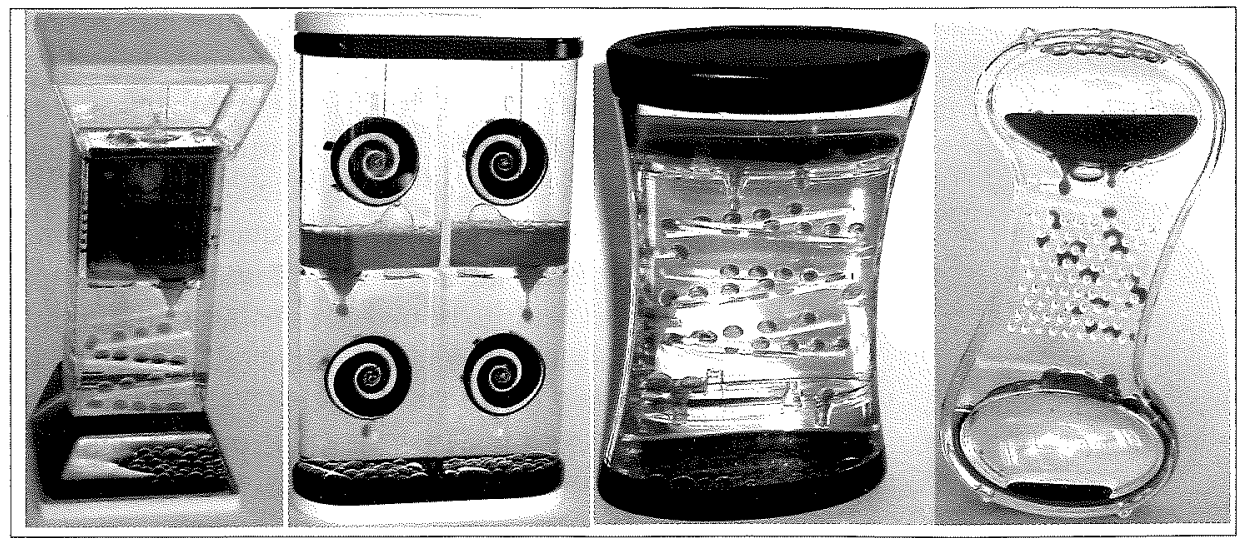

Fig. 5. Samples of density-driven fluids toys.

number. For comparison purposes, students can be engaged in an exercise to predict or calculate the Reynolds numbers for flow of water, oil, or other liquids under similar conditions, and the flow patterns can be observed for each of the other liquids as they are poured from their containers.

\section{Using toys in lab}

We use the toys during the first lab of the semester in our college junior-level fluid mechanics course for the specific purposes of requiring students to meet and work with their new lab mates, observing and intentionally thinking about properties and behaviors of fluids, and communicating to students the expectation of active participation in a fun learning process.

Examples of various density-driven toys used are shown in Fig. 5. The setup for this exercise is easy-provide one toy and one exercise sheet for each group of two to three students. To focus the discussion and to compel students to use their knowledge combined with careful observation, the exercise sheet includes at least five questions related to properties and behaviors of fluids. Sample questions are:

- Each toy contains two or more colors of liquid (including clear). Explain why some fluids rise while others fall.

- Explain why the fluid appears to move more quickly when you first flip the unit (for about 10 seconds) than later on.

- Why are the falling droplets approximately equal in size and why do they flow at an evenly spaced distance?

- During motion, why do the droplets stay in droplet form instead of forming a steady stream to flow through the liquid?

- When drops fall onto (or flow up into) their like liquid or the droplets catch up with the ones ahead of them, they do not mix immediately to form one bigger drop or join the existing pool. Explain why this occurs, and what causes the drops to finally coalesce or combine with the existing pool.

These questions can be modified to the level appropriate for the students, e.g., high school or college-level physics courses. Questions can be progressively more challenging, requiring students to observe the toy in a new way and think critically to explain the unexpected behaviors of fluids. Groups that finish quickly can swap their toy with another group. Bonus points can be awarded to groups who answer "challenge questions" or questions about more complex toys such as the Sandscape or Ooze Tube, as suggested in a related paper. ${ }^{28}$ Once all groups have completed the exercise, the instructor leads a discussion of students' observations and answers, emphasizing terminology.

In our case, the exercise also served as a useful snapshot of students' fundamental knowledge of fluids, as summarized in Table I. Analysis of the students' scores shows that $>85 \%$ could identify and explain fundamental properties and characteristics such as density differences and immiscibility. One-fifth to one-half of the students were also able to answer a question about surface tension and the velocities of droplets-i.e., that equal-sized droplets moved at the same rate down the incline. Twenty to 50 percent of the students were able to answer the more challenging questions about drop formation based on careful observation, personal experience, or both, because the topic had not yet been addressed in class. The same questions were used in 2011 and 2012, but as seen from the results shown in Table I, students in the 2012 class did not perform as well as students in 2011. Direct comparisons are difficult as different populations of students from four different majors were enrolled in the course: Civil Engineering, Mechanical Engineering, Engineering Physics, and Engineering Management. Consequently, students had different academic backgrounds and represented different cohorts. However, this short exercise can help the instructor determine students' familiarity with topics and use that knowledge to spend more or less class time on a topic, as needed. The toys can also provide a point of reference when covering related material later in the term.

Table I. Summary of student performance on questions about the toys.

\begin{tabular}{|l|c|c|}
\hline Topic Addressed & \% of corfect responses \\
\hline & $\mathbf{2 0 1 1}$ & $\mathbf{2 0 1 2}$ \\
\hline Number of groups & 20 & 18 \\
\hline Density differences among liquids & 95 & 85 \\
\hline Density of liquids vs gases & 50 & 20 \\
\hline $\begin{array}{l}\text { Surface tension, gravity-driven flows, fluid } \\
\text { velocity }\end{array}$ & 50 & 35 \\
\hline Drop formation & 50 & 20 \\
\hline Liquid films, drop coalescence & 70 & 60 \\
\hline
\end{tabular}




\section{Summary}

Children's toys, novelties, or science-based toys are fun to play with, but they can also be used to engage students in the learning process when accompanied by interactive exercises. Despite their simplicity, fluids toys can be used to demonstrate an array of simple to complex fluid characteristics and flow phenomena. Effective use of toys can help engage students, and this can help them look forward to the next class and future labs.

\section{References}

1. R. M. Felder and R. Brent, "Understanding student differences," J. Eng. Educ. 94 (1), 57-72 (2005).

2. R. M. Felder and J. Spurlin, "Applications, reliability and validity of the Index of Learning Styles," Int. J. Eng. Educ. 21 (1), 103-113 (2005).

3. G. Freier, "The use of demonstrations in physics teaching," Phys. Teach. 19 (6), 384-386 (Sept. 1981).

4. E. R. Pinkston, "The use of demonstrations in teaching introductory physics," Phys. Teach. 19 (6), 387-388 (Sept. 1981).

5. W. A. Hilton, "Demonstrations as an aid in the teaching of physics," Phys. Teach. 19 (6), 389-390 (Sept. 1981).

6. J. L. Gross, "Seeing is believing: Classroom demonstrations as scientific inquiry," J. Phys. Teach. Educ. Online 1 (3), 3-6 (2002).

7. A. Estes, "Shock and awe in the civil engineering classroom," $J$. Prof. Iss. Eng. Educ. Pr. 131 (1), 1-5 (Jan. 2005).

8. R. V. Schaaf and J. L. Klosky, "Classroom demonstrations in introductory mechanics," J. Prof. Iss. Eng. Educ, Pr. 131 (2), 83-89 (April 2005).

9. A. Murline, "Toys that teach," ASEE Prism Online 13 (7), (2004).

10. H. Levinstein, "The physics of toys," Phys. Teach. 20, 358--365 (Sept. 1982).

11. R. C. Turner, “Toys in physics teaching: Balancing man," Am. J. Phys. 55 (1), 84-85 (Jan. 1987).

12. R. Turner, " 100 years of physics and toys: Balancing toys," Phys. Teach. 30, 542-543 (Dec. 1992).

13. Julius Sumner Miller video on mechanical toys, http://www. youtube.com $/$ watch? $\mathrm{v}=\mathrm{LZ}$ HHpHWIDS8\&feature=related, accessed June 2013.

14. Demonstration of a variable pitch toy "hydro-drum," http:// www.youtube.com/watch? $\mathrm{v}=$ KIimDGtlo- $8 \&$ feature=related, accessed June 2013.

15. Water droplet filmed at 2000 frames per second, http://www. flixxy.com/water-drop.htm, accessed June 2013.

16. Various videos of fluid behavior, http://media.efluids.com/ galleries/all, accessed June 2013.

17. Desktop-sized physical models of river and sediment dynamics, http://www.emriver.com/, accessed June 2013.
18. T. von Karman and L. Edson, The Wind and Beyond (Little and Brown, Boston, 1967), pp. 37-38.

19. Photo of Wolfgang Pauli and Niels Bohr examining a tippe top can be accessed online at http://www.nbi.dk/ petersen/ Physics/physics.html, accessed June 2013.

20. H. Aref, S. Hutzler, and D. Weaire, "Toying with physics," Euro. Phys. News 38 (3), 23-26 (2007).

21. J. Guémez, C. Fiolhais, and M. Fiolhais, "Toys in physics lectures and demonstrations - A brief review," Phys. Educ. 44 (1), 53-64 (2009).

22. S. Shakerin, "Lotus effect toy," Phys. Teach. 49, 346-347 (Sept. 2011).

23. R. W. Welch, S. J. Ressler, and A. C. Estes, "A model for instructional design," J. Prof. Iss. Eng. Educ. Pr. 131 (3),167-171 (July 2005).

24. M. Abdulwahed and Z. K. Nagy, "Applying Kolb's experiential learning cycle for laboratory education," J. Eng. Educ. 98 (3), 283-294 (July 2009).

25. C. H. Crouch, A. P. Fagen, and J. P. Callen, "Classroom demonstrations: Learning tools or entertainment?" Am. J. Phys. 72 (6), 835-838 (June 2004)

26. D. R. Sokoloff and R. K. Thornton, "Using Interactive Lecture Demonstrations to create an active learning environment," Phys. Teach. 35, 340-347 (Sept. 1997).

27. S. Shakerin, "Potential value of toys in engineering education," Proceedings of the 2009 American Society for Engineering Education Pacific Southwest Section Meeting, San Diego, CA, March 19-20.

28. C. Saviz and S. Shakerin, “How does it work?': Using toys to inspire wonder and develop critical thinking skills in fluids mechanics," Proceedings of the American Society for Engineering Education Annual Conference and Exposition, Louisville, $\mathrm{KY}$, June 2010. (includes additional challenge questions)

29. L. Courbin and H. A. Stone, "Your wetting day," Phys. Today 60 (2), 84-85 (Feb. 2007).

30. Experiments in Fluid Mechanics, edited by R. A. Granger (Holt, Rinehart and Winston, New York, 1988), pp. 416-427.

Said Shakerin received his engineering education in Iran and the United States, and is a registered professional engineer in California. He has been with the University of the Pacific since 1986, where he is now professor of mechanical engineering. His interests include creating devices that exemplify beauty and complexity of fluid flows for the purpose of informal science education. sshakerin@pacific.edu

Camilla Saviz completed BS and MS degrees in mechanical engineering at Clarkson University and a PhD in civil and environmental engineering at U.C. Davis. She is a registered civil engineer in California. She is an associate professor in the civil engineering department at the University of the Pacific, where she has happly taught since 1999. csaviz@pacific.edu 